\title{
Cerrahi Alan Enfeksiyonlarının Değerlendirilmesi
}

\author{
Evaluation of Surgical Site Infections
}

\section{Selma ATEŞ ${ }^{1}$, Selçuk NAZİK ${ }^{2}$, Ahmet Rıza ŞAHİN ${ }^{2}$, Fadime KARDAŞ ${ }^{3}$, Ayşegül ERDOĞAN ${ }^{4}$}

${ }^{1}$ Doç. Dr. Kahramanmaraş Sütçü İmam Üniversitesi Tip Fakültesi Enfeksiyon Hastalıkları ve Klinik Mikrobiyoloji AD, KAHRAMANMARAŞ

${ }^{2}$ Dr. Öğr. Üyesi. Kahramanmaraş Sütçü İmam Üniversitesi Tip Fakültesi Enfeksiyon Hastalıkları ve Klinik Mikrobiyoloji AD, KAHRAMANMARAȘ

${ }^{3}$ Hemşire. Kahramanmaraş Sütçü İmam Üniversitesi Tıp Fakültesi Enfeksiyon Hastalıkları ve Klinik Mikrobiyoloji AD, KAHRAMANMARAŞ

${ }^{4}$ Dr. Öğr. Üyesi. Kahramanmaraş Sütçü İmam Üniversitesi Tip Fakültesi Halk Sağlığı AD, KAHRAMANMARAŞ

Öz

Amaç: Bu çalışmada operasyon sonrası cerrahi alan enfeksiyonu gelişen hastaların operasyon öncesi ve sonrası yaptığı uygulamalar ve konağa ait faktörlerin değerlendirilmesi amaçlanmıştır.

Gereç ve Yöntemler: Çalışma prospektif, kesitsel ve tanımlayıcı olarak planlandı. Kahramanmaraş Sütçü imam Üniversitesi Tip Fakültesi Hastanesinde farklı bölümler tarafından opere edilen ve enfeksiyon gelişen hastalar çalışmaya dahil edildi.

Bulgular: Çalışmaya 67 hasta dahil edildi (\% 59.7'si erkek, $\% 40.3$ 'ü kadın). Olguların \% 19.4'üne ( $n=13)$ preoperatif dönemde kan transfüzyonu yapılmıs iken, \% 80.6'sına ( $\mathrm{n}=54)$ kan transfüzyonu yapılmamıştır. Olguların \% 97'si $(n=65)$ preoperatif dönemde antiseptikli duş almış ve olguların \% 53.7'si ( $\mathrm{n}=36)$ preoperatif dönemde kıl temizliği yapmıştır. Operasyon sonrası yara yerinde enfeksiyon gelişen hastaların dağılımı incelendiğinde hastaların \% 61'inde Gram (-) bakteri, \% 25.5'inda Gram (+) bakteri ve \% 4.5'inde mantar üremesi saptanmıştır.

Sonuç: Cerrahi alan enfeksiyonları hastaların hastanede yatış süresini arttırarak, iş gücü kaybına ve ekonomik kayba neden olmaktadır. Cerrahi alan enfeksiyonlarının önlenebilir nedenlerdir. Bu nedenle gerekli önlemleri almak konusunda azami dikkat gösterilmelidir.

Anahtar Kelimeler: Cerrahi alan enfeksiyonu, konak faktörleri, preoperatif dönem

\section{GİRIS}

Cerrahi alan enfeksiyonu (CAE), operasyonu takiben 30-90 içinde ortaya çıkan enfeksiyondur. Modern cerrahi teknikleri ve tüm gelişmelere rağmen CAE'nin sıklığ 1 az değildir. Önemli mortalite ve morbidite nedeni olan CAE'de cilt florasinda bulunan Gram (+) bakteriler daha sık olmak üzere Gram (-) ve mantar enfeksiyonları da gözlenmektedir. Son ylllarda özellikle dirençli patojenlere bağlı olarak kolonizasyon ve bununla ilişkili olarak CAE'i görülmektedir. Cerrahi alan enfeksiyonu; hastaların hastanede daha uzun süre kalmasına, ek olarak antibiyotik kullanımına, tedavi maliyetinin artmasına ve iş gücü kaybına neden olmaktadır $(1,2)$.

$\mathrm{Bu}$ çalışmada opere olan ve enfeksiyon gelişen

\section{Abstract}

Objective: The aim of this study was to evaluate the preoperative and postoperative management of patients with surgical field infection and to evaluate the factors related to the host.

Material and Methods: The study was planned as prospective, cross-sectional and descriptive. Patients who were operated by different departments in the Faculty of Medicine of Kahramanmaraş Sütçü İmam University and who developed infection were included in the study.

Results: The study included 67 patients (59.7\% male, $40.3 \% \mathrm{fe}$ male). While $19.4 \%(n=13)$ of the cases had blood transfusion in the preoperative period, $80.6 \%(n=54)$ had no blood transfusions. $97 \%$ $(n=65)$ of the patients had antiseptic shower in the preoperative period and $53.7 \%(n=36)$ of the cases had hair cleansing preoperatively. When the distribution of the patients who developed infection at the wound site after the operation is examined, $61 \%$ Gram (-) bacteria, $25.5 \%$ Gram (+) bacteria and $4.5 \%$ fungus were found.

Conclusion: Surgical site infections increase the length of hospital stay and cause loss of labor and economic loss. Surgical site infections are preventable causes. Therefore, maximum attention should be given to taking the necessary measures.

Key Words: Surgical site infection, host factors, preoperative period.

hastaların operasyon öncesi ve sonrası yaptı̆̆ 1 uygulamalar ve konağa ait faktörlerin değerlendirilmesi amaçlanmıştır.

\section{GEREÇ VE YÖNTEMLER}

Çalışma prospektif, kesitsel ve tanımlayıcı olarak planlandi. Kahramanmaraş Sütçü İmam Üniversitesi Tip Fakültesi Hastanesinde farklı bölümler tarafından opere edilen ve enfeksiyon gelişen hastalar çalışmaya dahil edildi. Çalışma için hasta onam formu dolduruldu. Etik kurul onayı alındı

Çalışmaya dahil edilen olguların yaş, cinsiyet,

\section{Çalışma 28-31 Mart 2018 tarihleri arasında Antalya'da gerçekleştirilen XIX. Türk Klinik Mikrobiyoloji ve Infeksiyon Hastalıkları Kongresi'nde P99 numaralı poster olarak sunulmuştur}

$\begin{array}{ll}\text { İletişim: } & \begin{array}{l}\text { Dr. Selçuk NAZİK, Kahramanmaraş Sütçü İmam Üniver- } \\ \text { sitesi Tip Fakültesi, Enfeksiyon Hastalıkları ve Klinik } \\ \text { Mikrobiyoloji AD, Kahramanmaraş }\end{array} \\ \text { DOI: } & \mathbf{1 0 . 1 7 5 1 7 / k s u t f d . 4 6 7 3 8 1}\end{array}$

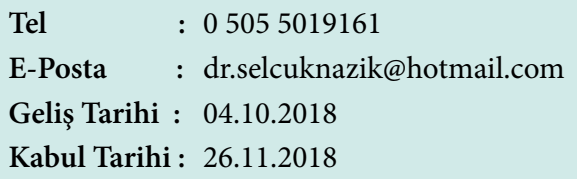


sigara kullanımı, komormidite durumu sorgulanarak kaydedildi. Ayrıca hastaların preoperatif dönemdeki hazırlı̆̆1 (cilt bakımı, kıllı bölgenin tıraş edilmesi, antiseptikli duş), operasyon süresi (dakika olarak) ve operasyon sonrası kullanılan pansuman (yapışkan pansuman) bilgileri kaydedildi.

Hastalarda enfeksiyona neden olan etkenler, postoperatif kaçınc1 günde enfeksiyonun geliştiği, tedavide kullanılan antibiyotikler ve tedavi süresi belirlenerek kaydedildi.

İstatistiksel Analiz: Çalışmada elde edilen verilerin istatistiksel değerlendirmesinde SPSS v.17.0 paket programı kullanıldı (SPSS Inc, Chicago, Illinois, USA). Sürekli veriler ortalama, standart sapma şeklinde özetlenirken, kategorik veriler sayı ve yüzde cinsinden özetlendi.

\section{BULGULAR}

Çalışmaya \% 59.7’si ( $n=40)$ erkek, \% 40.3'ü kadın $(\mathrm{n}=27)$ olmak üzere 67 hasta dahil edildi. Hastaların yaş ortalaması 50.1 \pm 24.6 yl (minimum-maksimum: 0-99 yll) idi.

Hastalaraait diyabetesmellitus(DM), malnütrisyon, malignite ve sigara kullanımı incelendiğinde olguların \% 35.8 'inde $(\mathrm{n}=24) \mathrm{DM}, \%$ 52.2'sinde $(\mathrm{n}=35)$ malnütrisyon ve $\% 20.9$ 'unda $(n=14)$ sigara kullanımı mevcuttu.

Operasyon sonrası yara yerinde enfeksiyon gelişen hastaların dağılımı incelendiğinde hastaların \% 61'inde Gram (-) bakteri, \% 25.5'inda Gram (+) bakteri ve $\% 4.5^{\prime}$ inde mantar üremesi saptanmıştır. Ayrica hastaların \% 9'unda ikili üreme saptanmıştır. İzole edilen mikroorganizmalar Tablo 1'de sunulmuştur.

Olguların \% 64.2'si ( $n=43)$ operasyon günü gelip ameliyata alınmış, \% 26.9'u $(\mathrm{n}=18)$ bir gün, $\% 4.5^{\prime} \mathrm{i}$ $(\mathrm{n}=3)$ iki gün ve $\% 4.5$ 'i $(\mathrm{n}=3)$ üç gün yatırıldıktan sonra ameliyata alınmıştır.

Olguların \% 19.4'üne ( $\mathrm{n}=13)$ preoperatif dönemde kan transfüzyonu yapılmış iken, \% 80.6'sına $(\mathrm{n}=54)$ kan transfüzyonu yapılmamıştır.

Olguların \% 97'si ( $\mathrm{n}=65)$ preoperatif dönemde antiseptikli duş almış ve olguların \% 53.7'si $(n=36)$ preoperatif dönemde kıl temizliği yapmıştır.

Operasyon süreleri incelendiğinde ortalama 228.0 \pm 140.9 dakika (minumum-maksimum:30-620 dakika) olduğu saptanmıştır.

\section{TARTIŞMA}

On dokuzuncu yüzyılın ikinci yarısında Joseph Lister tarafindan tanımlanan antisepsi kuralları ve sonrasında keşfedilen antibiyotikler CAE oranını azaltmıştır. Ancak bilinçsiz antibiyotik kullanımı, gelişen cerrahi teknik ve teknolojiye rağmen cerrahi prosedürde yaşanan aksaklıklar ve hatalar CAE oranını yeniden arttırmıştır (3). Cerrahi alan enfeksiyonlarının görülmesinde uygulanan cerrahi prosedür, operasyon süreci ve hastaya ait birçok risk faktörü bulunmaktadır.

Hastaya ait risk faktörlerinin başında yaş
Tablo 1: Cerrahi alan enfeksiyonuna neden olan etkenler

\begin{tabular}{|l|l|}
\hline Etken & $\%$ \\
\hline Monomikrobiyal & \\
\hline Gram (+) & \\
\hline MSSE & 1.5 \\
\hline MRSE & 6.0 \\
\hline VSE & 3.0 \\
\hline VRE & 6.0 \\
\hline MSSA & 4.5 \\
\hline MRSA & 1.5 \\
\hline KNS & 1.5 \\
\hline Streptococcus spp. & 1.5 \\
\hline Gram (-) & \\
\hline Enterobacteriaceae & 34.2 \\
\hline Pseudomonas aeruginosa & 7.5 \\
\hline Acinetobacter baumannii & 19.3 \\
\hline Fungal & \\
\hline C. albicans & 4.5 \\
\hline Polimikrobiyal & \\
\hline MRSA + A. baumannii & 1.5 \\
\hline E.coli + P. aeruginosa & 1.5 \\
\hline E. coli + MRSE & 1.5 \\
\hline E. coli + A. baumannii & 1.5 \\
\hline A. baumannii + Candida spp. & 1.5 \\
\hline A. baumannii + K. pneumoniae & 1.5 \\
\hline $\begin{array}{l}\text { MSSE: Metisiline duyarlı Staphylococcus epidermidis, } \\
\text { MRSE: Metisiline dirençli Staphylococcus epidermidis,VSE: } \\
\text { Vankomisin duyarlı enterokok, VRE: Vankomisin dirençli } \\
\text { enterokok, MSSA: Metisiline duyarlı Staphylococcus aureus, } \\
\text { MRSA: Metisiline dirençli Staphylococcus aureus, KNS: } \\
\text { Koagülaz Negatif Staphylococcus }\end{array}$ \\
\hline & \\
\hline
\end{tabular}

gelmektedir. Özellikle uç yaş gruplarında CAE oranı artmakta ve hastalığın mortalite ve morbiditesi daha ağır seyretmektedir $(4,5)$. Bir yaş altı ve $>50$ yaş hastaların operasyonları sonrasındaki CAE oranı 1-50 yaş arasındaki olgulara göre dört kat daha yüksek olduğu saptanmıştır (6). Çalışmamızdaki olguların yaş dağılımı incelendiğinde 1 yaşın altında 5 olgu, 65 yaş ve üzerinde ise 18 olgu mevcuttu. Tüm olguların \% 34.3'ü uç yaş grubunda idi.

Diyabet kontrolü ve glikoz regülasyonu operasyon öncesi sağlanmalıdır. Yüksek serum glikoz seviyesi doku iyileşmesinde etkili olan fibroblastların daha yavaş oluşumuna ve nötrofillerin kemotaksi ve fagositoz gibi fonksiyonlarında bozulmaya neden olmaktadır (7).

Taş ve ark. tarafından yapılan çalıșmada açı kalp cerrahisi geçiren hastalarda diyabet ve serum glikoz seviyesinin cerrahi alan enfeksiyonu ile ilişkisi araştırılmıştır (8). Operasyon sonrası enfeksiyon gelişen hastaların \% 26.7'sinde DM tanısı olduğu gözlenmiş. Sonuç olarak kan şekeri regülasyonu yapılmadan hastaların operasyona alınmaması gerekliliği vurgulanmıştır. Çalışmamızda CAE gelişen olguların \% 35.8'inde DM tanisi mevcuttu. 
Malnütrisyon ve CAE ile ilişkili CDC’nin bir önerisi olmamasına rağmen özellikle gastrointestinal malignite operasyonlarında CAE'nun malnütre hastalarda daha fazla görüldüğü saptanmıştır $(3,9)$ Benzer şekilde Klein ve ark. tarafindan operasyon öncesi nutrisyonel durumun postoperatif komplikasyonlar için bağımsız bir risk faktörü olduğu tespit edilmiştir (10). Malone ve ark. tarafından yapılan çalışmada cerrahiden önceki altı ayda kilo kaybetmenin CAE gelişimi için risk oluşturdu saptanmıştır (11). Çalışmamızda CAE olan olguların \% 38.8'inde malnütrisyon mevcuttu.

Sigara veya nikotin kullanımı ile primer yara iyileşmesinin geciktiği bununla ilişkili olarak CAE’nun görülme sıklığının arttığı bilinmektedir. Ayrıca sigara özellikle kardiyak cerrahi sonrasında önemli bir CAE risk faktörü olarak görülmektedir. Elektif yapılması planlanan operasyonlardan yaklaşık bir ay önce sigaranın bırakılması önerilmektedir $(3,12,13)$. Olgularımızın \% 20.9'u sigara kullanmaktaydı.

Operasyon sonrası gelişen enfeksiyonlarda cerrahi uygulanan bölgenin florası siklıkla CAE etkeni olarak karşımıza çıkmaktadır. Sıklıkla Gram (+) bakteriler etken olmaktadır. Bu bakterilerin başında da stafilokok ve streptokok gibi bakteriler gelmektedir. Hastane uzun yatan hastalarda dirençli bakteriler cilt florasında bulunabilir ve CAE etkeni olabilir (14). Yavuz ve ark. tarafindan sternal cerrahi yapılan hastalardaki CAE’nun değerlendirildiği bir çalışmada, olguların \% 65.3'ünde $(\mathrm{n}=313)$ gram $(+)$, $\%$ 30.1'inde ( $\mathrm{n}=144)$ Gram (-) ve olguların \% 4.6'sinda diğer etkenler olarak tespit edilmiştir (15). Bu çalışmada ise olguların yarısından fazlasinda (\% 65.9) Gram (-) bakteri üremesi saptanmıştır. Bu durum literatürdeki verilerle uyumlu değildir. Bunun nedeninin olguların daha çok abdominal cerrahi geçiren hastalardan oluşması ile ilişkili olduğu düşünülmüştür.

Preoperatif dönemde hastanede kalış süresinin uzun olması CAE oranını arttığı saptanmıştır. Operasyondan önce bir gün hastanede yatanda \% 6 CAE gelişirken, üç haftadan uzun yatanlarda bu oran \% 15 olarak hesaplanmıștır (3). Çalıșmamızda ise literatürün aksine yatış süresi ile CAE gelişimi arasında negatif bir korelasyon mevcuttu.

Heys ve ark. tarafindan yapilan bir derlemede kardiyak cerrahi geçiren hastalarda kan transfüzyonunun CAE gelişimi açısından bağımsız bir risk faktörü olduğu vurgulanmıştır. Buna karşın yapılan başka bir çalışmada ise bu durumun tersi savunulmuştur $(11,16)$. Çalışmamızda ise CAE gelişen olguların \%19.4'ünde kan transfüzyon öyküsü mevcuttu.

Preoperatif dönemde antiseptikli duş alınması ile ilgili olarak literatürde çelişkili veriler mevcuttur $(17,18)$. Çalışmamızda sadece iki hastada antiseptikli duş öyküsü mevcuttu.

Cerrahi öncesi kılların tıraş edilmesi ile ilgili olarak operasyondan ne kadar önce tıraş yapılırsa CAE daha fazla gözlenmektedir. Operasyon öncesi kilların tıraş edilmesi planlanacaksa tıraş makinesi, tüy dökücü krem veya makas kullanılması önerilmektedir. Buna karşın jilet gibi ciltte kesi oluşturan yöntemlerden uzak durulmalıdır (19). Seropian ve Reynolds tarafindan yapılan bir çalışmada preoperatif dönemde tüy dökücü krem ile tıraş bıçağı kullanımı kıyaslanmış. Tıraş bıçağı kullanımının CAE oranını yedi kat arttırdığı saptanmış (20). Çalışmamızda kıl temizliği yapan olgular CAE gelişen olguların \% 53.7'si idi.

Operasyon süresinin uzaması CAE gelişimini arttırmaktadır. Ayrıca operasyon süresinin uzaması cerrahın asepsi kurallarında hata yapmasina neden olabilir $(3,21)$. Çalışmamızda en uzun süren operasyon 620 dakika sürmüştür.

Cerrahi alan enfeksiyonları hastaların hastanede yatış süresini arttırarak, iş gücü kaybına ve ekonomik kayba neden olmaktadır. Cerrahi alan enfeksiyonlarının önlenebilir nedenler olabileceği unutulmadan gerekli önlemleri almak konusunda azami dikkat gösterilmelidir.

\section{KAYNAKLAR}

1. Tanner J, Padley W, Assadian O, Leaper D, Kiernan $\mathrm{M}$, Edmiston C. Do surgical care bundles reduce the risk of surgical site infections in patients undergoing colorectal surgery? Asystematic review and cohort meta-analysis of 8,515 patients. Surgery, 2015; 158 : 66-77.

2. Ulu AC. Cerrahi alan enfeksiyonları Turkiye Klinikleri J Inf Dis-Special Topics 2016; 9: 22-9.

3. Mangram AJ, Horan TC, Pearson ML, Silver LJ, Jarvis WR Guideline for prevention of surgical site infection,1999. AJIC 1999; 27: 97-134.

4. Moro ML, Toni A, Stolfi I, Carrieri MP, Braga M, Zunin C. Risk factors for nosocomial sepsis in newborn intensive and intermediate care units. Eur J Pediatr 1996; 155: 315-22.

5. Yalçın AN. Nozokomiyal Sepsis: Risk faktörleri, hastanede yatış süresi, ek maliyet, prognozu etkileyen faktörler ve mortalite. Hastane İnfeksiyonları Dergisi 1998; 2: 230-6.

6. Bozfakioğlu Y. Cerrahi alan infeksiyonlarında patogenez ve siniflama. Hastane İnfeksiyonları Dergisi 2001; 5: 91-4.

7. Kao LS, Meeks D, Moyer VA, Lally KP. Peri-operative glycaemic control regimens for preventing surgical site infections in adults. Cochrane Database Syst Rev. 2009; 8: CD006806.

8. Taş S, Dönmez AA, Tunçer EY, Adademir T, Yanartaş M, Sunar H. Açık kalp cerrahisi hastalarında diyabet ve kan glukozu kontrolünün cerrahi alan enfeksiyonları üzerine etkisi. Koşuyolu Kalp Dergisi 2013; 16: 199-204.

9. Fukuda Y, Yamamato K, Hiroa M, Nishikawa K, Maeda S, Haraquchi N, et al. Prevalance of malnutrition among gastric cancer patients undergoing gastrectomy and optimal preoperative nutritional support for preventing surgical site infections. Annals of Surgical Oncology 2015; 22: 778-85.

10. Klein JD, Hey LA, Yu CS, Klein BB, Coufal FJ, Young EP, et al. Perioperative nutrition and postoperative complications in patients undergoing spinal surgery. 
Spine 1996; 21: 2676-82.

11. Malone DL, Genuit T, Tracy JK, Gannon C, Napolitano LM. Surgical site infections: reanalysis of risk factors. J Surg Res 2002; 103: 89-95.

12. Meng F, Cao J, Meng X. Risk factors for surgical site infection following spinal surgery. Journal of Clinical Neuroscience 2015; 22: 1862-6.

13. Mangram, AJ, Horan TC, Pearson ML, Silver LC, Jarvis WR. CDC Guideline for prevention of surgical site infection, 1999. Infection Control and Hospital Epidemiology 1999; 20: 247-278.

14. Nathens AB, Dellinger EP. Surgical site infections. Current Treatment Options in Infectious Diseases 2000; 2: 347-358.

15. Yavuz SŞ, Tarçın O, Ada S, Dinçer F, Toraman S, Birbudak $S$, et al. Incidence, aetiology, and control of sternal surgical site infections. J Hosp Infect. 2013; 85: 206-12.

16. Heys SD, Walker LG, Smith I, Eremin O. Enteral nutritional supplementation with key nutrients in patients with critical illness and cancer: A metaanalysis of randomized controlled clinical trials. Ann Surg 1999; 229:4 67-77.
17. Garibaldi RA, Skolnick D, Lerer T, Poirot A, Graham J, Krisuinas E, et al. The impact of preoperative skin disinfection on preventing intraoperative wound contamination. Infect Control Hosp Epidemiol 1988; 9: 109-113.

18. Earnshaw JJ, Berridge DC, Slack RC, Makin GS, Hopkinson BR. Do preoperative chlorhexidine baths reduce the risk of infection after vascular reconstruction. Eur J Vasc Surg 1989; 3: 323-326.

19. Chosky SA, Modha D, Taylor GJ. Optimisation of ultraclean air. The role of instrument preparation. J Bone Joint Surg Br 1996; 78: 835-7.

20. Seropian R, Reynolds BM. Wound infections after preoperative depilatory versus razor preparation. Am J Surg. 1971; 121: 251-4.

21. Culver DH, Horan TC, Gaynes RP, Martoni WJ, Jarvis WR, Emori TG, et al. Surgical wound infection rates by wound class, operative procedure, and patient risk index. Am J Med 1991; 91: 152-7. 